\title{
Methods used in the United Kingdom for the culture of micro-organisms from blood
}

\author{
D F J Brown, S F Perry
}

\begin{abstract}
Aims: To survey blood culture methods in use in the United Kingdom.

Methods: A questionnaire was distributed to the 415 United Kingdom laboratories participating in the clinical bacteriology subscheme of the UK National External Quality Assessment Scheme for Microbiology.

Results: Two hundred and eighty seven laboratories completed the questionnaire. The responses indicated wide variations in methods used including considerable differences among laboratories using the same basic methods. The most widely used techniques were the Bactec and conventional broth systems.

Conclusions: Although many published comparisons have failed to show that any basic method is outstandingly successful in the isolation of all organisms, there is evidence that several factors can contribute to good performance. In some laboratories suboptimal conditions were in use. The variations in technique probably reflect differences in practical suitability of a system for any particular laboratory, costs, and personal preferences.
\end{abstract}

The culture of micro-organisms from blood is one of the most important procedures undertaken in clinical microbiology laboratories. Despite extensive published findings detailing the effects of technical factors on the isolation of micro-organisms from blood cultures there is apparently no consensus on what technique should be used. Cost and suitability of methods for the requirements of individual laboratories probably largely influence the choice of a particular system as there is no evidence that any single system is outstanding. A wide variety of commercial systems is now marketed, ${ }^{12}$ but there is no published information on blood culture practices in the United Kingdom. As part of the UK National External Quality Assessment Scheme for Microbiology (UKNEQAS) we have surveyed blood culture methods currently used in the United Kingdom.

\section{Methods}

In June 1989 a questionnaire was distributed to the 415 United Kingdom laboratories participating in the clinical bacteriology subscheme of the UKNEQAS. Completed questionnaires were returned by 287 laboratories. Not all questions were answered by all laboratories and some responses were unclear, in which case the reply was not included in the analysis.

\section{Results}

NUMBER OF BLOOD CULTURES PROCESSED

The numbers of cultures processed in different laboratories ranged from six to 18500 bottle sets a year, with a mean of 2651 . The number of blood cultures processed a year (number of laboratories testing) was less than 100 (13), 100-999 (54), 1000-1999 (58), 2000-2999 (72), 3000-3999 (27), 4000-4999 (24), 5000-5999 $(9), 6000-6999(12), 7000-7999(7), \geqslant 8000$ (7).

VOLUME OF BLOOD CULTURED

From adults, 217 of 287 laboratories cultured blood volumes of $10 \mathrm{ml}$ or less and only two laboratories cultured greater than $20 \mathrm{ml}$ (table 1). The volume of blood cultured was related to the method used as very few Bactec or Signal users claimed to culture specimens of greater than $10 \mathrm{ml}$ while almost all Septi-Chek users and a third of laboratories with conventional systems cultured over $10 \mathrm{ml}$ blood. Smaller volume blood samples were likely to be cultured from paediatric or neonatal patients (table 1).

\section{METHOD OF COLLECTION OF BLOOD SAMPLE}

For 271 of 287 laboratories blood was collected by use of a syringe and needle and transferred directly to the blood culture bottles. Vacutainers were used by only eight laboratories and only one used a transfer set. Six laboratories used different methods in different situations.

\section{BLOOD CULTURE SYSTEMS USED}

Several laboratories used combinations of blood culture systems, so a total of 327 systems were used in the 287 laboratories (table 2). Conventional broth systems were used by 94 laboratories, $77 \%$ of which purchased bottles from commercial sources. Forty four labora-

Table 1 Volume of blood cultured

\begin{tabular}{lccl}
\hline & \multicolumn{3}{l}{$\begin{array}{l}\text { Number of laboratories culturing blood } \\
\text { from }\end{array}$} \\
\cline { 2 - 4 } $\begin{array}{l}\text { Volume of blood } \\
\text { ml })\end{array}$ & Adults & Children & Neonates \\
\hline$\leqslant 2$ & 1 & 19 & 49 \\
$2 \cdot 5-5$ & 14 & 41 & 34 \\
$5 \cdot 5-10$ & 202 & 116 & 56 \\
$10 \cdot 5-20$ & 44 & 11 & 5 \\
$20 \cdot 5-30$ & 2 & 0 & 0 \\
As available & 2 & 45 & 78 \\
Not stated & 22 & 55 & 65 \\
\hline
\end{tabular}


Table $2 \quad$ Blood culture systems used (327 systems in 287 laboratories)

\begin{tabular}{|c|c|c|}
\hline Type of system & Source & $\begin{array}{l}\text { Number } \\
\text { of } \\
\text { laboratories } \\
\end{array}$ \\
\hline Conventional broth & $\begin{array}{l}\text { Lab M } \\
\text { Medical Wire } \\
\text { Gibco } \\
\text { Southern Group } \\
\text { Beckton Dickinson } \\
\text { Difco } \\
\text { Home made } \\
\text { Not stated }\end{array}$ & $\begin{array}{r}24 \\
12 \\
10 \\
10 \\
9 \\
4 \\
24 \\
1\end{array}$ \\
\hline $\begin{array}{c}\text { Diphasic (Casteneda, } \\
\text { paddle or dipslide) }\end{array}$ & $\begin{array}{l}\text { Roche Septi-Chek } \\
\text { Southern Group } \\
\text { API } \\
\text { Lab M } \\
\text { Home made } \\
\text { Not stated }\end{array}$ & $\begin{array}{r}26 \\
7 \\
1 \\
2 \\
6 \\
2\end{array}$ \\
\hline Positive pressure & Oxoid Signal & 62 \\
\hline Machine based & $\begin{array}{l}\text { Bactec } 460 \\
\text { Bactec } 660 \\
\text { Bactec } 730 \\
\text { Malthus }\end{array}$ & $\begin{array}{r}87 \\
18 \\
18 \\
1\end{array}$ \\
\hline Lysis centrifugation & Dupont Isolator & 3 \\
\hline
\end{tabular}

tories used diphasic systems, some of which were commercially produced dipslide or paddle systems. The most popular of these, the Roche Septi-Chek system (BCB system), was used by 26 laboratories. The Oxoid Signal system, in which positive pressure caused by gas production indicates positive cultures, was used in 62 laboratories. Of the 124 laboratories using machine based systems, 105 laboratories used radiometric Bactec systems (Bactec 460 and 660) and 18 used the infra-red Bactec 730 system. The Dupont Isolator, a lysis centrifugation system, was used by only three laboratories as their principal system. Pour plates were used by only 14 laboratories, in combination with other systems.

NUMBER OF BOTTLES INOCULATED

Most laboratories $(n=211)$ inoculated two bottles, the most common distinction between bottles being that one was aerobic and the other anaerobic. Forty nine of 59 laboratories inoculating only a single bottle used the Signal system. Sixteen laboratories used three bottle systems.

\section{MEDIUM USED}

Tryptone soy broth (TSB) was used in one or more bottles in 238 laboratories. Brain heart infusion (BHI) broth was the next most popular medium, used in 70 laboratories. Other basic media used were fastidious anaerobe broth in 34 laboratories, thioglycollate broth and supplemented peptone digest broth each in 28 laboratories, enriched soybean casein broth in 15 laboratories and other media in 21 laboratories. Most laboratories used similar media under anaerobic and aerobic conditions, but some used specific anaerobic formulations such as LabM fastidious anaerobe broth or thioglycollate broth.

Sodium polyanethol sulphonate (SPS or liquoid) was present in the aerobic bottle only in 79 laboratories, in the anaerobic bottle only in 10 laboratories, in both bottles in 159 laboratories and in no media in 22 laboratories.
INACTIVATION OF ANTIMICROBIAL AGENTS

Media containing resins which absorb antimicrobial agents were used by only two laboratories. Media containing $\beta$-lactamases were used by $49(17 \%)$ laboratories, although it was unclear whether it was added to all cultures or only to selected cultures. In 35 laboratories the enzyme was added after the blood sample, in nine before the sample, in five either before or after, or the time of addition was not stated. The amount of enzyme added was very variable. The sources of the $\beta$-lactamases (number of laboratories) were Genzyme $(n=17)$, Oxoid $(n=10)$, Porton Products $(n=6)$, BBL $(n=$ $4)$, Loch Light $(n=2)$, Difco $(n=2)$, and not stated $(n=6)$.

\section{INCUBATION OF BLOOD CULTURES}

Most commonly, culture sets included one aerobic bottle and one anaerobic bottle (table 3). Gas mixtures, including carbon dioxide, were widely used. Of 273 laboratories using aerobic bottles, 37 vented bottles in the laboratory, 180 did not, and 56 failed to indicate whether bottles were vented or not. Various methods of venting were used of which the Difco subvent (13 laboratories) was most common. Other methods of venting were loosening of the cap $(n=8)$, Vacutainer $(n=5)$, syringe and needle $(n=4)$, membrane $(n=1)$, and cap loosened and vent unit $(n=1)$. Five laboratories did not state how bottles were vented.

Two hundred and thirty seven laboratories incubated cultures at $37^{\circ} \mathrm{C}, 28$ at $36^{\circ} \mathrm{C}$, and 15 at $35^{\circ} \mathrm{C}$

Table 3 Atmosphere in headspace of blood culture bottles

\begin{tabular}{lll}
\hline & \multicolumn{2}{l}{$\begin{array}{l}\text { Number of laboratories with } \\
\text { indicated atmosphere in the }\end{array}$} \\
\cline { 2 - 3 } Headspace atmosphere & First bottle & Second bottle \\
\hline Air & 58 & 20 \\
$2 \cdot 5 \% \mathrm{CO}_{2}$ in air & 27 & 0 \\
$4 \cdot 5 \% \mathrm{CO}_{2}$ in air & 97 & 17 \\
$10 \% \mathrm{CO}_{2}$ in air & 27 & 0 \\
$5 \% \mathrm{CO}_{2}, 21 \% \mathrm{O}_{2}, 74 \% \mathrm{~N}_{2}$ & 5 & 0 \\
$5 \% \mathrm{CO}_{2}, 5 \% \mathrm{O}_{2}, 90 \% \mathrm{~N}_{2}$ & 1 & 0 \\
$10 \% \mathrm{CO}_{2}, 20 \% \mathrm{O}_{2}, 70 \% \mathrm{~N}_{2}$ & 1 & 0 \\
$5 \% \mathrm{CO}_{2}, 95 \% \mathrm{~N}_{2}$ & 4 & 37 \\
$10 \% \mathrm{CO}_{2}, 80 \% \mathrm{~N}_{2} \dagger$ & 0 & 25 \\
$10 \% \mathrm{CO}_{2}, 3 \% \mathrm{H}_{2}, 80 \% \mathrm{~N}_{2} \dagger$ & 0 & 13 \\
$10 \% \mathrm{CO}_{2}, 10 \% \mathrm{H}_{2}, 80 \% \mathrm{~N}_{2}$ & 0 & 42 \\
$5 \% \mathrm{CO}_{2}, 4 \% \mathrm{H}_{2}, 91 \% \mathrm{~N}_{2}$ & 0 & 6 \\
“Anaerobic" & 1 & 23 \\
\hline
\end{tabular}

^First and second bottles usually corresponded with aerobic and anaerobic bottles.

tGas mixture not totalling $100 \%$ recorded as stated by the tGas mixture
laboratories.

Table 4 Period of incubation during which blood cultures were shaken

\begin{tabular}{lcc}
\hline & \multicolumn{2}{c}{ Number of laboratories shaking the } \\
\cline { 2 - 3 } Time bottles are shaken & Aerobic bottle & Anaerobic bottle \\
\hline 3-6 hours & 0 & 3 \\
12 hours & 2 & 1 \\
12-24 hours & 0 & 1 \\
24 hours & 53 & 10 \\
24-48 hours & 4 & 0 \\
48 hours & 67 & 7 \\
2-7 days & 24 & 0 \\
Intermittent intervals & & \\
through a 12 hour & 5 & 0 \\
period & 0 & 1 \\
Intermittent intervals & & \\
\hline
\end{tabular}


Table 5 Time of reading of Bactec blood cultures

\begin{tabular}{llc}
\hline & \multicolumn{2}{c}{ Number of laboratories reading the } \\
\cline { 2 - 3 } Time bottles are read & Aerobic bottle & Anaerobic bottle \\
\hline Once daily & 13 & 54 \\
Twice daily & 21 & 9 \\
Twice in first 24 hours then once daily & 17 & 9 \\
Twice daily in first 48 hours then once daily & 41 & 14 \\
Twice daily in first 48 hours then intermittent & 7 & 24 \\
Twice in first 24 hours then intermittent & 10 & 0 \\
2-3 times daily in first 48 hours then once daily & 9 & 5 \\
Other & 0 & 3 \\
\hline
\end{tabular}

Most laboratories $(n=178)$ discarded bottles after incubation for seven days. In other laboratories the number of days' incubation (number of laboratories) was less than 5 (3), 5-6 (39), 8-10 (32), 14-21 (16). In five laboratories the incubation time depended on the type of bottle and in 14 the incubation period was not stated. Ninety nine laboratories indicated that incubation would be extended if necessary for isolation of particular organisms such as Brucella.

SHAKING OF BLOOD CULTURE BOTTLES

Bactec aerobic bottles were shaken in 109 $(99 \%)$ of 110 laboratories and $17(16 \%)$ of 108 laboratories shook Bactec anaerobic bottles. Signal bottles were shaken in 30 of 49 laboratories. With the Septi-Chek system four of 19 laboratories shook aerobic bottles and two of the 19 shook anaerobic bottles. Three of 56 laboratories using other systems shook aerobic bottles and two of the 56 shook anaerobic bottles. There was considerable variation in the duration of time for which bottles were shaken (table 4) but most laboratories did not shake bottles for more than $\mathbf{4 8}$ hours.

\section{ROUTINE EXAMINATION OF CULTURES}

There was considerable variation in the timing of examination of bottles in the Bactec system (table 5). Most laboratories examined bottles twice daily in the first two days of incubation and once daily thereafter.

Most laboratories operating conventional systems visually examined cultures once daily (table 6). With systems such as Signal and Septi-Chek, where the manufacturers recommended more frequent examinations, cultures were more likely to be examined twice daily. Forty two laboratories supplemented the machine reading of Bactec bottles with visual inspections at various times.

Most laboratories operating conventional systems subcultured without visual evidence of microbial growth (blind subculture) but at various times (table 7). Blind subculture of Bactec and Signal bottles was generally done only when indicated by the clinical situation. The most common methods of subculture were to use a loop or a syringe and needle, but subvent units were also popular (table 8). The media most commonly used for blind subcultures were blood agar alone or blood agar plus chocolate agar (table 9). Subcultures for

Table 6 Time of visual inspection of blood cultures

\begin{tabular}{lllllll}
\hline & \multicolumn{7}{l}{ Number of laboratories using: } & & \\
\cline { 2 - 7 } Time of inspection & Bactec & Signal & Septi-Chek & Conventional & Other & $>1$ system \\
\hline Once daily & 22 & 10 & 5 & 34 & 4 & 18 \\
Twice daily & 4 & 16 & 9 & 5 & 2 & 3 \\
Three times daily & 1 & 5 & 2 & 1 & 0 & 0 \\
Four times daily & 0 & 1 & 0 & 0 & 0 & 1 \\
At 24-48 hours only & 1 & 0 & 0 & 0 & 1 & 0 \\
At 6 and 24 hours & 2 & 0 & 0 & 6 & 0 & 1 \\
In first 24 hours only & 2 & 0 & 1 & 0 & 0 & 0 \\
Hourly during day & 7 & 0 & 0 & 2 & 0 & 4 \\
Depends on bottle & 10 & 0 & 2 & 0 & 0 & 5 \\
Other & 15 & 8 & 1 & 0 & 1 & 1 \\
Not done & 36 & 0 & 0 & & 0 &
\end{tabular}

Table 7 Time of blind subculture of blood cultures

\begin{tabular}{|c|c|c|c|c|c|c|}
\hline \multirow[b]{2}{*}{ Time of subculture } & \multicolumn{6}{|c|}{ Number of laboratories using: } \\
\hline & Bactec & Signal & Septi-Chek & Conventional & Other & $>1$ system \\
\hline $\begin{array}{l}24 \text { hours only } \\
48 \text { hours only } \\
72 \text { hours only } \\
\text { Other } \\
\text { Depends on bottle } \\
\text { Special cases only } \\
\text { Not done }\end{array}$ & $\begin{array}{r}0 \\
6 \\
0 \\
7 \\
2 \\
26 \\
39\end{array}$ & $\begin{array}{r}1 \\
4 \\
0 \\
0 \\
1 \\
10 \\
1\end{array}$ & $\begin{array}{r}0 \\
1 \\
1 \\
2 \\
12 \\
1 \\
1\end{array}$ & $\begin{array}{r}11 \\
5 \\
0 \\
36 \\
2 \\
0 \\
0\end{array}$ & $\begin{array}{l}0 \\
0 \\
0 \\
1 \\
2 \\
0 \\
0\end{array}$ & $\begin{array}{r}0 \\
2 \\
1 \\
9 \\
12 \\
0 \\
5\end{array}$ \\
\hline
\end{tabular}

Table 8 Method of blind subculture of blood cultures

\begin{tabular}{|c|c|c|c|c|c|c|}
\hline \multirow[b]{2}{*}{ Method of subculture } & \multicolumn{6}{|c|}{ Number of laboratories using: } \\
\hline & Bactec & Signal & Septi-Chek & Conventional & Other & $>1$ system \\
\hline $\begin{array}{l}\text { Loop } \\
\text { Pasteur pipette } \\
\text { Difco subvent } \\
\text { Syringe and needle } \\
\text { Dip slide } \\
\text { Swab } \\
\text { Other } \\
\text { > 1 method } \\
\text { Depends on bottle }\end{array}$ & $\begin{array}{r}0 \\
0 \\
15 \\
19 \\
0 \\
0 \\
0 \\
0 \\
0\end{array}$ & $\begin{array}{r}16 \\
7 \\
0 \\
9 \\
0 \\
1 \\
1 \\
0 \\
0\end{array}$ & $\begin{array}{l}5 \\
1 \\
0 \\
3 \\
3 \\
0 \\
0 \\
0 \\
6\end{array}$ & $\begin{array}{r}20 \\
5 \\
4 \\
18 \\
0 \\
0 \\
0 \\
3 \\
6\end{array}$ & $\begin{array}{l}1 \\
0 \\
0 \\
2 \\
0 \\
0 \\
2 \\
1 \\
2\end{array}$ & $\begin{array}{r}7 \\
2 \\
4 \\
10 \\
0 \\
1 \\
0 \\
1 \\
5\end{array}$ \\
\hline
\end{tabular}




\begin{tabular}{|c|c|c|c|}
\hline \multirow[b]{2}{*}{ Agar media } & \multicolumn{3}{|c|}{ Number of laboratories performing: } \\
\hline & $\begin{array}{l}\text { Blind } \\
\text { subculture }\end{array}$ & $\begin{array}{l}\text { Terminal } \\
\text { subculture }\end{array}$ & $\begin{array}{l}\text { Subculture of } \\
\text { suspected } \\
\text { positive cultures }\end{array}$ \\
\hline Blood & 36 & 38 & 34 \\
\hline Blood + chocolate & 70 & 55 & 57 \\
\hline Blood + chocolate + MacConkey & 11 & 14 & 60 \\
\hline Chocolate & 7 & 1 & 0 \\
\hline Blood + MacConkey & 3 & 5 & 19 \\
\hline Blood + chocolate + CLED & 2 & 1 & 12 \\
\hline Blood + MacConkey + chocolate + fastidious anaerobe & 1 & 0 & 8 \\
\hline Blood + chocolate + MacConkey + kanamycin blood & 1 & 0 & 5 \\
\hline Blood + chocolate + CLED + neomycin blood & 1 & 0 & 4 \\
\hline Blood + Wilkins Chalgren & 3 & 1 & 4 \\
\hline Chocolate + blood with anaerobic supplements & 3 & 0 & 0 \\
\hline Blood + chocolate + Sabaroud & 3 & 3 & 0 \\
\hline Blood + chocolate + MacConkey + malt & 7 & 1 & 3 \\
\hline Blood + CLED & 1 & 0 & 3 \\
\hline Blood + chocolate + Wilkins Chalgren & 0 & 0 & 3 \\
\hline Blood + chocolate + MacConkey + Wilkins Chalgren & 0 & 0 & 5 \\
\hline Blood + MacConkey + neomycin blood & 0 & 0 & 3 \\
\hline Other ( $\leqslant 2$ laboratories using each) & 27 & 21 & 37 \\
\hline Not specified as depends on result of Gram stain & 0 & 0 & 16 \\
\hline
\end{tabular}

Table 10 Atmosphere of incubation for subcultures

\begin{tabular}{|c|c|c|c|c|c|c|}
\hline \multirow[b]{3}{*}{ Atmosphere } & \multicolumn{6}{|c|}{ Number of laboratories performing: } \\
\hline & \multicolumn{2}{|c|}{ Blind subculture of: } & \multicolumn{2}{|c|}{ Terminal subculture of: } & \multicolumn{2}{|c|}{$\begin{array}{l}\text { Subculture of suspected } \\
\text { positive cultures in: }\end{array}$} \\
\hline & $\begin{array}{l}\text { Aerobic } \\
\text { bottle }\end{array}$ & $\begin{array}{l}\text { Anaerobic } \\
\text { bottle }\end{array}$ & $\begin{array}{l}\text { Aerobic } \\
\text { bottle }\end{array}$ & $\begin{array}{l}\text { Anaerobic } \\
\text { bottle }\end{array}$ & $\begin{array}{l}\text { Aerobic } \\
\text { bottle }\end{array}$ & $\begin{array}{l}\text { Anaerobic } \\
\text { bottle }\end{array}$ \\
\hline Air & 6 & 0 & 4 & 0 & 7 & 0 \\
\hline $\mathrm{Air}+\mathrm{CO}_{2}$ & 36 & 9 & 26 & 7 & 57 & 11 \\
\hline Air and air $+\mathrm{CO}_{2}$ & 4 & 16 & 1 & 0 & 15 & 5 \\
\hline Anaerobic & 0 & 32 & 0 & 23 & 0 & 51 \\
\hline Air and anaerobic & 9 & 3 & 12 & 4 & 13 & 15 \\
\hline $\mathrm{Air}+\mathrm{CO}_{2}$ and anaerobic & 69 & 54 & 57 & 43 & 92 & 101 \\
\hline Air, air $+\mathrm{CO}_{2}$ and anaerobic & 19 & 0 & 17 & 10 & 67 & 68 \\
\hline
\end{tabular}

aerobic bottles were incubated aerobically only $(32 \%)$ or both aerobically and anaerobically $(68 \%)$ (table 10). Subcultures from anaerobic bottles were incubated anaerobically only $(28 \%)$, aerobically only $(22 \%)$, or both aerobically and anaerobically (50\%) (table 10$)$.

Of the 287 laboratories, 118 subcultured all bottles at the end of the incubation period (terminal subcultures). In 13 laboratories terminal subcultures were limited to the aerobic bottle, and 14 subcultured only if clinical circumstances indicated that this might be useful. Most of the 137 laboratories not including terminal subcultures used the Bactec sys-

Table 11 Direct identification tests on positive blood cultures

\begin{tabular}{lc}
\hline & Number of \\
Identification test & laboratories \\
\hline API for Gram-negative rods & 36 \\
Mast ID for Gram negative rods & 2 \\
Sensititre for Gram negative rods & 1 \\
Individual carbohydrate tests for Gram negative rods & 2 \\
API for Gram positive cocci & 1 \\
Mast ID for Gram positive cocci & 1 \\
Latex kit for streptococcal grouping & 27 \\
Latex kit for Staphylococcus aureus & 4 \\
Latex kit for $S$ pneumoniae & 19 \\
Latex kit for group B streptococci & 3 \\
Latex kit for S pneumoniae, $N$ meningitidis, and $H$ influenzae & 7 \\
Latex kit for $S$ pneumoniae and $H$ influenzae & 2 \\
Latex kit for N meningitidis & 1 \\
Latex kit for unspecified organisms & 58 \\
Coagulase test & 22 \\
Endonuclease test & 12 \\
Optochin/capsule swelling test & 7 \\
X and V growth factors & 2 \\
Nagler reaction & 2 \\
Aesculin test & 3 \\
CIE & 1 \\
Mastring ID for Gram negative anaerobic rods & 1 \\
Not stated or dependent on Gram stain & 8 \\
\hline
\end{tabular}

tem. Media used for terminal subcultures were similar to those used for blind subcultures (table 9), but a higher proportion of laboratories $(66 \%)$ incubated subcultures from anaerobic bottles both aerobically and anaerobically (table 10).

All 266 responding laboratories subcultured bottles suspected to be positive but 66 did not subculture other bottles in the set if only a single bottle was suspected. The range and variety of media used to subculture bottles suspected to be positive were greater than those used for blind subcultures (table 9). Selective or indicator media were the most common additions to blood agar and chocolated blood agar. Most laboratories incubated subcultures in similar atmospheres to those used for terminal subcultures (table 10).

\section{DIRECT IUËNTIFICATION AND ANTIMICROBIAL SUSCEPTIBILITY TESTS}

Two hundred and seventy eight (96.9\%) laboratories examined Gram stained smears from suspected positive blood cultures. Further direct identification tests were used by close to half the laboratories on at least some occasions (table 11). A wide variety of tests was used of which latex agglutination tests for various organisms were most common. Endonuclease or coagulase tests on staphylococci and direct inoculation of API tests for identification of Enterobacteriaceae were each used in close to $12 \%$ laboratories. Direct antimicrobial susceptibility tests were done in $\mathbf{2 7 6}$ (96.2\%) laboratories. 
PROPORTION OF CULTURES POSITIVE

The percentage of cultures positive, including contaminants, ranged from $1 \%$ to $40 \%$ with a mean of $12 \%$. The percentage of cultures positive (number of laboratories) was 1-5\% (17), 6-10\% (70), 11-15\% (74), 16-20\% (30), $21-25 \%(6), 30-40 \%$ (2). Contamination rates were estimated at between 0 and $25 \%$, with a mean of $5 \%$. The percentage of cultures contaminated (number of laboratories) was $\leqslant 2 \%$ (50), 3-4\% (42), 5-6\% (57), 7-8\% (16), 9-10\% (11), $11-25 \%$ (4). The mean rate for significant positive cultures was $7 \%$. There was no significant correlation between either percentage of cultures positive or contamination rate and the system used or the number of blood cultures processed.

\section{Discussion}

The number of blood cultures processed will be influenced by the size and type of hospital in which the laboratory is situated, features that this survey did not distinguish. Laboratories dealing with only small numbers of blood cultures every year will find it difficult to ensure that the system is operating efficiently. Reports of positivity rates vary widely and do not always distinguish contaminants from significant positive isolates. One survey in the United States of America found a mean of close to $10 \%$ positive cultures of which about $25 \%$ were contaminated, ${ }^{3}$ which gives a similar significant positive rate and a slightly lower contamination rate than in our survey. Systems with low contamination rates are clearly desirable, not only because of the difficulty in judging the clinical importance of contaminating organisms, but also because contamination results in considerable additional work in processing the cultures.

The isolation rate from blood cultures increases significantly with the volume of the blood sample. . $^{42}$ Increasing the volume of blood sample is recognised as the most significant factor in increasing the isolation rate from blood cultures. ${ }^{21213}$ Washington recommended a blood sample of $20-30 \mathrm{ml}^{13}$ and clearly most laboratories are failing to adopt this recommendation. Commercial systems which limit the volume of blood to be added, either by instruction or by physical restraint, are a clear disincentive to the use of larger volume samples. Inoculation of more than one set at the same time would overcome the problem but this is unlikely to be widely practised because of the extra expense involved.

The wide range of different systems in use suggests that no single method has proved to be outstanding in performance or practical for use in all laboratories. Conventional broth systems are still widely used, despite the availability of various alternative commercial systems. Although commercial systems offer potential advantages in terms of labour saving and novel detection systems, they have not been shown to isolate significantly more micro-organisms or provide results any earlier than good conventional systems. Diphasic systems have the advantage that subculture is achieved simply by tilting the bottle so that the broth washes over the agar medium. One disadvantage is that it may be difficult to see small colonies through the container. Good results have been reported for the Septi-Chek diphasic system. ${ }^{14-16}$ The Bactec system, although not fully automated, is the only widely used machine based system. One laboratory used an automated Malthus conductivity monitoring system, although it is not marketed for use with blood cultures. Other automated machines for screening blood cultures, such as the Organon Teknika BacT/ Alert and Difco Sentinel systems, have recently been introduced so the range of automated systems in use may change in the near future. The Oxoid Signal system is novel in using pressure from gas production by micro-organisms to give an easily read indication of positive cultures. It is also unusual in that it is a single bottle system. Evaluations of the performance of the Signal method have generally been encouraging, with some inconsistent reports of limitations. ${ }^{17-20}$ The Isolator system compares well with other blood culture methods, ${ }^{21} 22$ and is particularly useful in the isolation of fungi ${ }^{23}$ and for cultures of blood from patients on antimicrobial treatment. ${ }^{24}$ It is, however, a technically demanding method in that the specimen must be processed before incubation. Several laboratories used combinations of methods, presumably to combine the benefits or overcome the limitations of the different systems.

As the range of organisms likely to be recovered from blood cultures is wide and the growth requirements variable, more than one bottle is commonly inoculated. The Signal system is designed as a single bottle system, and as described above, compares favourably with other methods. Thirteen of the 49 laboratories using Signal system used it in combination with a second system. Increasing the number of bottles inoculated may improve isolation rates by increasing the volume of blood cultured as well as the range of cultural conditions.

Pour plates might provide earlier identification results for some blood cultures as colonies may be available for further investigation after overnight incubation. However, they are time consuming to set up, require technical processing at the time blood is taken, are subject to possible contamination due to the manipulation involved, and low level bacteraemia will often be missed due to the small volume of blood used in this method.

The predominance of TSB as the basic medium used for blood cultures reflects the use of the medium in commercial systems. BHI broth was less commonly used but has been shown to have equivalent performance to TSB. $^{6}$ The antibacterial activity of blood may be decreased by diluting blood 1 in 10 or more in the culture medium or by adding sodium polyanethol suphonate. ${ }^{624}$ In most laboratories the systems used include SPS as part of the medium formulation and have blood culture bottles with small volumes such that the dilution of blood in medium is less than 1 in 10 . The inhibitory effects of SPS on Neisseria spp are significant ${ }^{25} 26$ and, if possible, bottles without 
SPS should be included in the set if these organisms are likely to be present. SPS also inhibits the growth of some anaerobic cocci, ${ }^{27}$ although this inhibition is medium dependent. ${ }^{28}$ The inhibitory effects of SPS may be partially reversed by addition of gelatin. ${ }^{29}$ Gelatin was not claimed to be used in media by any of the laboratories surveyed, although it is present in the medium used in the Signal system. $^{30}$ The beneficial effects of SPS for isolation of many common organisms probably far outweigh its detrimental effects on Neisseria and anaerobic cocci.

Most laboratories rely on dilution of the blood sample in the culture medium to eliminate antimicrobial activity, but in many cases this may be inadequate. Media containing resins which remove antimicrobial agents are available with the Bactec system but the effectiveness of the resins is unclear. ${ }^{24}$ Prospective addition of $\beta$-lactamase to media increases isolation rates, ${ }^{31}$ but it is expensive and increases the risk of contamination.

Aerobic and facultative anaerobic organisms grow better in bottles with an aerobic atmosphere in the headspace. Although obligate anaerobes may grow in a bottle with air in the headspace but reducing agents in the medium, anaerobes grow better with an anaerobic atmosphere in the headspace. ${ }^{32}{ }^{33}$ Carbon dioxide was commonly part of the gas mixture in the headspace, presumably to promote the growth of carboxyphilic organisms, and because many organisms grow better when incubated in an atmosphere containing carbon dioxide, although to our knowledge any advantage of this addition in relation to blood cultures has not been proved. Only $14 \%$ of laboratories claimed to vent aerobic bottles, but as venting is an integral part of the Septi-Check and Signal systems the number of laboratories actually venting bottles was much higher.

Most laboratories incubated blood cultures at $37^{\circ} \mathrm{C}$. Growth of some organisms is inhibited at $37^{\circ} \mathrm{C},{ }^{34}$ and control of incubator temperatures may not be exact, so it may be advantageous routinely to incubate cultures at a temperature slightly below $37^{\circ} \mathrm{C}$.

Shaking bottles in the early period of incubation has been shown to improve recovery rates and speed of recovery of some organisms in Bactec, ${ }^{35}$ Septi-Chek, ${ }^{35}$ and Signal systems. ${ }^{36}$ It is likely that the benefits of shaking bottles during incubation could be applied to all broth systems although this may prove impractical. Detection of significant micro-organisms rarely requires incubation of cultures for more than seven days, although prolonged incubation may be necessary if cultures are negative and patients have persistent symptoms, ${ }^{637}$ or if a slow growing organism such as Brucella is suspected. This was reflected in the practice of most laboratories, who extended incubation beyond seven days only when clinical circumstances suggested that this might be useful.

More frequent reading of bottles in the first 24 hours has been shown to result in earlier detection of positive blood cultures ${ }^{38}$ and this is common practice with those using Bactec. With some commercial systems, including Sig- nal and Septi-Chek, twice daily readings are recommended and most users of these systems complied with the recommendations. The advantages of earlier detection by more frequent inspection of bottles would apply equally to conventional systems, although this was not generally practised. With the Signal system the facility for more frequent reading was taken to extreme in seven laboratories, where hourly visual examinations through the day were undertaken. It is difficult to believe that such frequent readings are productive, particularly as these frequent examinations were not continued outside conventional working hours. Visual inspection of Bactec bottles, carried out by $35 \%$ Bactec users, eliminates the time-saving benefit of the automated reading. False negative results with the Bactec system are uncommon, ${ }^{39}$ but visual inspection might detect these.

Blind subculture of aerobic bottles within the first 24 hours has been shown to be productive, ${ }^{40}$ but additional blind subcultures are unlikely to be useful in most situations. Despite evidence that there is little benefit in blind subculture for anaerobes, ${ }^{41}$ the practice was routine in at least a third of laboratories. Blind aerobic subcultures of anaerobic or unvented bottles, carried out by 82 laboratories, are generally unproductive, ${ }^{41}$ unless Haemophilus influenzae is present. ${ }^{42}$

Most laboratories using Bactec did not include a routine terminal subculture, a practice shown to be of little value with this method. ${ }^{39}$ Although the value of terminal subcultures has not been formally assessed with other systems, the performance of most of them is equivalent to that of Bactec and it is unlikely that terminal subcultures are of real practical value.

Sixty six laboratories subcultured only the suspected positive bottles in a set. With over $50 \%$ of positive blood cultures, evident growth in one bottle in a set is likely to be paralleled by growth in the other bottles in the set. ${ }^{6}$ The availability of results from all bottles in a set is also of value in distinguishing contamination with some organisms. Hence culture of all bottles in a set is desirable even if only a single bottle shows evidence of microbial growth.

The methods used to subculture bottles are largely influenced by practical considerations in that where a cap can be easily removed from a bottle a loop or Pasteur pipette are likely to be used. With bottles which do not have easily removable caps penetration of the septum via a needle is the more commonly used subculture method. Subculture of anaerobic bottles by any method allowing air into the bottles is likely to affect adversely the subsequent recovery of anaerobic organisms so subculture in an anaerobic cabinet or use of a syringe and needle is advisable. The diphasic systems effectively are subcultured at each inspection by tilting the bottles to swirl broth over the solid medium. This process is less likely to contaminate cultures than invasive subcultures used with some other systems, and presents savings in both labour and media.

Direct tests on suspected positive blood 
cultures could be valuable in providing an early identification of the infecting organism. Gram staining was applied in $97 \%$ of laboratories and is clearly a useful procedure as it may give an indication of the identity of the infecting organism and guide the selection of further direct identification tests and antimicrobial susceptibility tests. While direct identification tests are desirable, several of the tests applied were not designed for direct use on blood cultures and as a consequence their performance is unknown. For example, we are not aware of any evaluation of the performance of the API system with organisms suspended in blood culture medium rather than the suspension medium recommended for the kits. The early results afforded by direct antimicrobial susceptibility tests are desirable but care should be taken in interpreting results. In particular, cultures may be mixed, inocula may be incorrect, and antagonistic components of the medium, such as $\beta$-lactamase, may affect the activity of antimicrobial agents. Tests should be repeated once pure cultures are available.

The survey has shown considerable variation in methods used for processing blood cultures in laboratories in the United Kingdom. Although many published comparisons of methods have failed to show that any basic method is outstanding for isolation of all organisms, there were several details of technique which could be improved in some laboratories. It is likely that the variability in technique among laboratories is a reflection of cost, personal preferences, and practical suitability of a method for use in any particular laboratory.

1 Shanson DC. Modern blood culture techniques and other methods for detecting microbes in the blood. In: Shanson DC, ed. Septicaemia and endocarditis. Clinical and microbiological aspects. Oxford: Oxford University Press, 1989:76-102.

2 Freeman R. Blood cultures- principles, practice and pitfalls. Rev Med Microbiol 1990;1:92-100.

3 Morello JA. Blood culture practices currently in use. In Balows A and Sonnenworth AC, eds. Bacteremia. Laboratory and clinical aspects. Springfield: Thomas, 1983:61-95.

4 Fox H, Leaman WG. Observation on blood cultures with a special reference to the quantity of the blood used. $J$ Lab Clin Med 1926;11:145-50.

5 Hall MM, Ilstrup DM, Washington JA. Effect of volume of blood cultured on detection of bacteremia. $J$ Clin Microbiol 1976;3:643-5.

6 Washington JA. Conventional approaches to blood culture. In: Washington JA, ed. The detection of septicemia. West Palm Beach: CRC Press, 1978:41-87.

7 Sandven P, Høiby A. The importance of blood volume cultured on detection of bacteraemia. Acta Pathol Microbiol Scand, Sect B 1981;89:149-52.

8 Tenney JH, Reller B, Mirrett S, Wang WL, Weinstein MP. Controlled evaluation of the volume of blood cultured in detection of bacteremia and fungemia. J Clin Microbiol 1982;15:558-61.

9 Ilstrup DM, Washington JA. The importance of volume of blood cultured in the detection of bacteremia and fungemia. Diagnost Microbiol Infect Dis 1983;1:107-10.

10 Shanson DC, Thomas F, Wilson D. Effect of volume of blood cultured on detection of Streptococcus viridans blood cultured on detection of Streptococe

11 Plorde JJ, Tenover FC, Carlson LG. Specimen volume versus yield in the BACTEC blood culture system. J Clin Microbiol 1985:22:292-5.

12 Washington JA. The microbiological diagnosis of infective endocarditis. J Antimicrob Chemother 1987;20 (supp A):29-36.

13 Washington JA. Blood cultures: An overview. Eur J Clin Microbiol Infect Dis 1989;8:803-6.

14 Pfaller MA, Sibley TK, Westfall LM, Hoppe-Bauer JE, Keating MA, Murray PR. Clinical laboratory comparison of a slide blood culture system with a conventional broth system. J Clin Microbiol 1982;16:272-5.
15 Weinstein MP, Reller LB, Mirrett S, Wang WL, Alcid DV. Clinical comparison of an agar slide blood culture bottle Clinical comparison of an agar slide blood culture bottle with tryptic soy broth and a conventional blood culture bottle with supplemented peptone broth. J Clin Microbiol Kim MJ, Gottschall R, Schwabe LD, Randell E. Effect of agitation and frequent subculturing on recovery of aerobic and facultative pathogens by Roche Septi-check and Bactec blood culture systems. J Clin Microbiol 1987; 25:312-5.

17 Murray PR, Niles AC, Heeren RL, Curren MM, James LE, Hoppe-Bauer JE. Comparative evaluation of the Oxoid Signal and Roche Septi-Check blood culture systems. $J$ Clin Microbiol 1988;26:2526-30.

18 Himmelreich CA, Orlando MF, Storch GA. Comparison of the Oxoid Signal blood culture system with supplemented peptone broth in a pediatric hospital. J Clin Microbiol peptone broth in
$1989 ; 27: 1262-5$.

19 Rohner P, Auckenthaler R. Comparative evaluation of the BCB Roche and Oxoid Signal blood culture systems. Eur $J$ Clin Microbiol Infect Dis 1989;8:150-3.

20 Schwabe LD, Randell EL, Miller-Catchpole R, Squires CI, Gottschall RL. A comparison of the Oxoid Signal with nonradiometric BACTEC NR-660 for detection of bacteremia. Diagnost Microbiol Infect Dis 1990;13:3-8.

21 Henry NK, Grewell CM, Van Grevenhof PE, Ilstrup DM, Washington JA. Comparison of lysis-centrifugation with a biphasic blood culture medium for the recovery of aerobic and facultatively anaerobic bacteria. J Clin Microbiol and facultatively

22 Brannon $P$, Kiehn TE. Large scale clinical comparison of the lysis-centrifugation and radiometric systems for blood culture. J Clin Microbiol 1985;22:951-4.

23 Murray PR. Comparison of the lysis-centrifugation and agitated biphasic blood culture systems for the detection of fungemia. J Clin Microbiol 1991;29:96-8.

24 Washington JA, Ilstrup DM. Blood cultures: Issues and controversies. Rev Infect Dis 1986;8:792-802.

25 Eng J. Effect of sodium polyanethol sulfonate in blood cultures. J Clin Microbiol 1975;1:119-23.

26 Eng J, Iveland $\mathrm{H}$. Inhibitory effect in vitro of sodium polyanethol sulfonate on the growth of Neisseria meningitidis. J Clin Microbiol 1975;1:444-7.

27 Graves MH, Morello JA, Kocka FE. Sodium polyanethol sulfonate sensitivity of anaerobic cocci. Appl Microbiol 1974;27:1131-3.

28 Shanson DC. An experimental assessment of different anaerobic blood culture methods. J Clin Pathol 1974; 27:273-9.

29 Eng J, Holten H. Gelatin neutralization of the inhibitory effect of sodium polyanethol sulfonate on Neisseria meningitidis in blood culture media. J Clin Microbiol 1977; 6:1-3.

30 Sawhney D, Hinder S, Swaine D, Bridson EY. Novel method for detecting micro-organisms in blood cultures. J Clin Pathol 1986;39:1259-63.

31 Brown DFJ, Warner M, Taylor CED, Warren RE. Prospective addition of $\beta$-lactamase to blood culture medium. tive addition of $\beta$-lactamase to
$J$ Med Microbiol 1988;26:147-52.

32 Tenney JH, Reller B, Mirrett S, Weinstein MP, Wang WL. Controlled evaluation of the effect of atmosphere of incubation on detection of bacteraemia and fungemia in supplemented peptone broth. J Clin Microbiol 1982;16: 437-42.

33 Ilstrup DM, Washington JA. Effects of atmosphere of incubation on recovery of bacteria and yeasts from blood cultures in tryptic soy broth. Diagnost Microbiol Infect Dis 1983;1:215-9.

34 Isenberg HD, Washington JA, Balows A, Sonnenwirth AC Collection, handling, and processing of specimens. In: Lennette EH, Balows A, Hausler WJ, Shadomy HJ, eds. Manual of clinical microbiology, 4th edn. Washington DC Manual of clinical mic

35 Kim MJ, Gottschall RL, Schwabe LD, Randall EL. Effect of agitation and frequent subculturing on recovery of aerobic and facultative pathogens by Roche Septi-Chek and BACTEC blood culture systems. J Clin Microbio 1987;25:312-5.

36 Weinstein MP, Mirrett S, Reimer LG, Reller LB. Effect of agitation and terminal subcultures on yield and speed of detection of the Oxoid Signal blood culture system versus the BACTEC radiometric system. J Clin Microbiol 1989; 27:427-30.

37 Washington JA. The microbiological diagnosis of infective endocarditis. J Antimicrob Chemother 1987;20 (Suppl A): 29-36.

38 Anhalt JP. New or experimental approaches to detection of bacteremia. In: Washington JA, ed. The detection of septicemia. West Palm Beach: CRC Press, 1978:109-44.

39 Gill J. Lack of clinical relevance in routine terminal subculturing of blood cultures. J Clin Microbiol 1981;14:116-8.

40 Sliva HS, Washington JA. Optimal time for routine early subculture of blood cultures. J Clin Microbiol 1980 12:576-8.

41 Pfaller MA, Westfall LM, Murray PR. Value of routine aerobic subculturing of unvented blood culture bottles. $J$ Clin Microbiol 1983;17:601-4.

42 Henry NK, Washington JA. Initial detection of bacteremia by subculture of unvented tryptic soy broth blood culture bottles. Diagnost Microbiol Infect Dis 1984;2:107-11. 